\title{
Survey Tentang Kebijakan Pemerintah Terhadap Jarak Sekolah dengan Rumah Menurut Prespektif Orang Tua
}

\author{
Ernida Rayani \\ Universitas Lambung Mangkurat, Indonesia \\ Email:1710127120005@mhs.ulm.ac.id
}

\section{INFORMASI ARTIKEL}

Terkirim 25-Juni-2020

Revisi 19-Okt-2020

Diterima 30-Nov-2020

\section{Kata kunci:}

Kebijakan Pemerintah,

Sekolah, Jarak

\begin{abstract}
ABSTRAK
The school is a formal institution to gain knowledge, the school plays an important role in achieving the goals of national education Every parent would want their children to go to a favorite school, proper school. Even though the school is far from where they live. environment close to children. According to (Verdiyani, 2016) strategic location and proximity to schools are the main factors parents in choosing schools. In accordance with government policies related to the zoning system this applies to children with special needs. Where children with special needs can attend school in accordance with their residence. This study aims to find out how parents' views are related to government policies, where students should study near their homes.
\end{abstract} Padang.

\section{Pendahuluan}

Pendidikan sangat penting guna membangun peradaban bangsa, hal ini disadari betul oleh pemerintah betapa perlunya peningkatan pendidikan yang ada di Indonesia saat ini Melalui pendidikan diharapkan mampu meningkatkan kualitas SDM (Sumber Daya Manusia) yang akan berdampak kepada masa depan bangsa yang maju (Khoirul Syani et al., 2018).

Sekolah merupakan lembaga pendidikan formal yang menyelenggarakan kegiatan belajar dan mengajar serta menerima dan memberi pelajaran sesuai dengan tingkat jurusan dan sebagainya, yang memiliki unsusr pendukung sesuai aturan yang berlaku. Dalam menentukan sekolah diperlukan perencanaan yang benar-benar matang, karena pendidikan sangat penting dalam kehidupan. Banyak faktor yang mempengaruhi peserta didik dalam pemilihan sekolah. (Lestari et al., 2019)

Setiap orang tua pasti menginginkan anaknya untuk bersekolah di sekolah favorit, disekolah yang layak. Menurut (Verdiyani,2016) lokasi yang strategis dan dekat dengan sekolah menjadi faktor utama orang tua dalam memilih sekolah. Lokasi sekolah yang dekat dapat memudahkan siswa untuk menjangkau sekolah tersebut.. Meskipun sekolah tersebut berada jauh dari tempat tinggal mereka. Hampir semua orang tua ingin mendidik anaknya di lingkungan sebaik mungkin dan keputusan mereka untuk berinvestasi pada anak tergantung pada sejumlah faktor sosial, ekonomi dan budaya (Maangi, 2014: 119-128).

Masyarakat sebagai orang tua calon siswa memiliki andil besar dalam penentuan sekolah anaknya. Pemilihan sekolah yang sesuai dengan kebutuhan anak sangat penting karena sekolah merupakan tempat anak menghabiskan banyak waktu untuk bertumbuh dan berkembang. Sekolah menjadi lingkungan yang dekat dengan anak. Pemerintah telah mengeluarkan kebijakan tentang sistem zonasi, sistem zonasi ini merupakan sistem yang mengharuskan sekolah untuk menerima semua calon peserta didik yang mendaftar sesuai zonasinya tanpa terkecuali.

Adapun tujuan dari kebijakan pemerintah ini sebenarnya adalah untuk pemerataan pendidikan agar tidak adalagi yang namanya sekolah favorit, semua sekolah itu sama. Hal ini nampaknya juga 
berlaku untuk anak-anak berkebuthan khusus. Dengan adanya kebijakan pemerintah ini, memberikan kesempatan kepada anak berkebutuhan khusus dapat bersekolah di sekolah inklusif yang dekat dengan tempat tinggalnya. Anak Berkebutuhan Khusus tidak harus bersekolah di SLB, apabila SLB tersbut masih dapat dijangkau oleh ABK maka hal ini tidak jadi masalah. Tetapi, lain halnya jika di tempat tinggal ABK tidak ada sekolah khusus atau SLB, tentu hal ini akan jadi masalah bagi ABK yang harus menempuh jarak jauh agar dapat bersekolah di SLB.

Menurut Sunaryo (dalam Nurfatah \& Arafat, 2017) Pendidikan inklusi merupakan pendidikan untuk semua, dimana anak berkebutuhan khusus dapat bersekolah di sekolah reguler yang berada dekat dengan tempat tinggalnya. Adapun menurut (Yuwono \& Utomo, 2016) Sekolah Inklusif merupakan sekolah siaga, maksudnya adalah sekolah reguler harus siap menerima anak berkebutuhan khusus. Keberadaan pendidikan inklusi bukan saja penting untuk menampung anak yang berkebutuhan khusus dalam sebuah sekolah yang terpadu, melainkan pula dimaksudkan untuk mengembangkan potensi dan menyelamatkan masa depan mereka dari diskriminasi pendidikan yang cenderung mengabaikan anak-anak berkelainan (Takdir dalam Jauhari, 2017).

Pendidikan inklusif itu sendiri adalah pembelajaran yang ramah bagi semua peserta didik baik anak pada umumnya maupun anak-anak dengan berkebutuhan khusus. Sekolah tidak berhak membeda-bedakan peserta didik karena semua siswa mendapatkan pelayanan pendidikan yang sama, termasuk anak berkebutuhan khusus yang juga berhak mendapatkan pendidikan yang sama seperti anak reguler pada umumnya (Yuwono, 2017).

Beberapa orangtua beralasan memasukkan anaknya ke Layanan Pendidikan Inklusif agar anaknya mendapatkan perlakuan yang sama dalam bidang pendidikan, adapula yang memasukkan anaknya karena faktor jarak dan keterbatasan lembaga pendidikan yang diperuntukkan untuk anakanak dengan kebutuhan khusus. Selain itu, sekolah inklusif menjadi alternatif para orang tua dari anak berkebutuhan khusus. hingga alasan bahwa anaknya bukanlah anak dengan kebutuhan khusus sehingga anak tersebut tidak disekolahkan di sekolah luar biasa, namun di sekolah formal umum dengan layanan pendidikan inklusi (Primadata et al., 2015).

\section{Metode}

Pendekatan yang digunakan pada penelitian ini ialah pendekatan deduktif dengan jenis penelitian kualitatif. Proses pengumpulan data dilakukan dengan melakukan survei primer berupa penyebaran kuesioner kepada orang tua/wali murid untuk mengetahui faktor yang mempengaruhi pemilihan sekolah dasar menurut persepsi orang tua/wali murid dan kepala sekolah untuk mengetahui karakteristik sekolah. Sampel sekolah yang digunakan pada penelitian ini ialah sebanyak 130 sampel, sedangkan jumlah sampel responden orang tua/wali murid adalah sebesar 161 sampel.

\section{Hasil dan Pembahasan}

\section{Karakteristik Faktor yang Mempengaruhi Pemilihan Sekolah}

Dari hasil penyebaran kuesioner, dapat dilihat bahwa jarak dari rumah kesekolah sangat beragam dengan yang paling dekat sekitar 50 meter dan jarak terjauh mencapai $12.000 \mathrm{~m}$. Jarak dari rumah ke sekolah kurang dari 500 meter sebanyak 28\% persen, kemudian jarak rumah dan sekolah 500-1 km sebanyak 55\%, dan yang terakhir jarak rumah dan sekolah 1-5km sebnyak 13\%. Dapat disimpulkan bahwa mayoritas jarak tempuh responden dari rumah kesekolah adalah sebesar lebih dari 500 meter hingga $1 \mathrm{~km}$. Jarak ini tergolong sebagai jarak yang mudah untuk dijangkau oleh anak. Kemudian ketersediaan sarana dan prasarana pada sekolah di diasumsikan dapat dilihat pada penilaian status akreditasi masing- masing sekolah mengingat salah satu hal yang dinilai pada proses akreditasi meliputi standar sarana prasarana yang di dalamnya. 
Dari data penilaian standar sarana prasarana sekolah yang ada, didapatkan persentase sekolah yang sudah memenuhi standar sarana prasarana. Sebanyak $47 \%$ sekolah sudah menyediakan sarana prasarana yang baik.

Berdasarkan analisis faktor yang telah dilakukan, kelompok faktor jarak dari rumah dapat dikatakan sebagai kelompok faktor yang paling dominan terhadap keputusan pemilihan sekolah. Kelompok faktor kedua merepresentasikan lokasi dan jam belajar sekolah, dengan sub-faktor jarak dari rumah ke sekolah, tingkat aksesibilitas sekolah, lokasi sekolah aman dan nyaman, dan efektivitas waktu belajar mengajar. Berdasarkan pengamatan yang dilakukan di lapangan, lokasi sekolah yang dipilih oleh orang tua/wali murid masih tergolong dalam lokasi sekolah yang dapat dijangkau oleh anak.

Beberapa faktor menunjukkan keputusan pemilihan sekolah diantaranya adalah faktor lokasi dan sarana prasarana. Sejalan dengan penelitian yang di lakukan oleh Saputri et al., (2018) menunjukkan bahwa terdapat 3 sub faktor yang menjadi keputusan dasar dalam memilih sekolah yaitu, faktor pertama adalah terkait ketersediaan sarana dan prasarana ramah anak, proses belajar mengajar yang ramah anak, adanya partisipasi anak dalam kegiatan belajar mengajar, adanya kebijakan sekolah ramah anak, pendidik dan tenaga kependidikan terlatih hak-hak anak, dan adanya partisipasi pihak terkait dalam perwujudan sekolah ramah anak. Kemudian faktor kedua adalah jarak dari rumah ke sekolah, tingkat aksesibilitas sekolah, lokasi sekolah aman dan nyaman, dan efektivitas waktu belajar mengajar. Dan faktor ketiga yaitu fasilitas tambahan yang tidak disediakan oleh semua sekolah, yakni ketersediaan sarana transportasi umum dan adanya program makan siang di sekolah. Selain itu, faktor lain yang menjadi pertimbangan dalam memilih sekolah ialah faktor kefavoritan sekolah atau sekolah favorit hal ini sejalan dengan penelitian yang di lakukan oleh Amirin et al., (2016) menunjukkan faktor utama dalam memilih sekolah ialah tingkat kefavoritan sekolah.

Untuk itu, dalam rangka memeratakan pendidikan, pemerintah mengeluarkan kebijakan zonasi, dimana pada kebijakan ini, peserta didik harus bersekolah yang dekatdengan tempat tinggalnya. Dengan adanya sistem zonasi ini, diharapkan tidak adalagi sekolah favorit. Diharapkan biaya akomodasi siswa untuk menuju sekolah dapat lebih kecil. Sistem zonasi sekolah juga dapat membuat peserta didik yang pintar bisa menyebar di sekolah sekolah. Dengan demikian siswa pintar bisa membantu siswa yang kesulitan dalam belajar. (Bintoro, 2018). Kebijakan pemerintah ini tentunya juga menguntungkan bagi anak berkebutuhan khusus. Dimana mereka dapat bersekolah di sekolah inklusi, yang dekat dengan tempat tinggalnya.

\section{Kesimpulan}

Banyak faktor yang menjadikan orang tua dalam memilih sekolah untuk anaknya diantaranya adalah faktor jarak fasilitas sekolah dan lingkungan sekolah yang menjadi faktor utama dalam memilih sekolah, orang tua lebih banyak memilih sekolah untuk anaknya yang dekat dengan rumah. Beberapa orang tua menyetujui kebijakan pemerintah terkait pemilihan sekolah yang dekat dengan tempat tinggal selain memeratakan sistem pendidikan hal ini juga menguntungkan orang tua yang memiliki anak berkebutuhan khusus di mana anak berkebutuhan khusus dapat bersekolah di sekolah umum bersama anak reguler pada umumnya, mereka dapat bersekolah di sekolah yang jaraknya dekat dengan tempat tinggal mereka, selain itu mereka juga tidak perlu menempuh jarak yang jauh untuk bersekolah ke SLB Karena tidak semua tempat tinggal ABK dekat dengan SLB

\section{Daftar Rujukan}

Amirin, T. M., Wijayanti, W., \& Abd. Jabar, C. S. (2016). Kondisi Insani Dan Material Sekolah Menengah Negeri "Pilihan Kedua" Di Kota Yogyakarta. Jurnal Penelitian Ilmu Pendidikan, 9(1), 1-11. https://doi.org/10.21831/jpipfip.v9i1.10686 
Bintoro, R. F. A. (2018). Public Perception Regarding Policy Implementation On School Zoning Policy In The Acceptance Of High School New Students Year 2017/2018 In Samarinda. Jurnal Riset Pembangunan, 1(20), 48-57.

Fuadi, K. (2015). Analisis Kebijakan Penyelenggaraan Pendidikan Inklusif di Provinsi DKI Jakarta. HIKMAH Journal of Islamic Studies.

Jauhari, A. (2017). Pendidikan Inklusi Sebagai Alternatif Solusi Mengatasi Permasalahan Sosial Anak Penyandang Disabilitas. Jurnal IJTIMAIYA, 1.

Khoirul Syani, A., Mufid, S., \& Hazin, M. (2018). Komunikasi dalam Implementasi Kebijakan Pendidikan Wajib Belajar 9 Tahun di Kecamatan Ngadiluwih. KHAZANAH PENDIDIKAN. https://doi.org/10.30595/jkp.v11i1.2309

Lestari, I. P., Sobri, A. Y., \& Kusumaningrum, D. E. (2019). ANALISIS FAKTOR-FAKTOR YANG MEMPENGARUHI PESERTA DIDIK DALAM PEMILIHAN SEKOLAH LANJUTAN TINGKAT ATAS (SLTA). Jurnal Administrasi Dan Manajemen Pendidikan. https://doi.org/10.17977/um027v2i32019p167

Nurfatah, N., \& Arafat, Y. (2017). Pendidikan Inklusi Sebagai Implementasi Nilai-Nilai Karakter Bangsa. Jurnal Manajemen, Kepemimpinan, Dan Supervisi Pendidikan, 2(2), 230867. https://doi.org/10.31851/jmksp.v2i2.1472

Primadata, A. P., Soemanto, R., \& Haryono, B. (2015). Tindakan Orangtua Dalam Menyekolahkan Anak Berkebutuhan Khusus Pada Layanan Pendidikan Inklusif di Sekolah Dasar Negeri 1 Tanjung, Kecamatan Purwokerto Selatan, Kota Purwokerto. Jurnal Analisa Sosiologi.

Saputri, R. D., Putri, R. A., \& Rini, E. F. (2018). Faktor-faktor yang Mempengaruhi Pemilihan Sekolah Dasar dalam Mendukung Kota Surakarta Layak Anak. Region: Jurnal Pembangunan Wilayah Dan Perencanaan Partisipatif, 13(2), 152. https://doi.org/10.20961/region.v13i2.21172

Septhevian Program Studi Manajemen, R., Tjiptono, F., Pembimbing Progam Sudi Manajemen, D., \& Partisipasi Murni, A. (2007). Faktor-Faktor Yang Mempengaruhi Keputusan Orangtua Dalam Memilih Sekolah Dasar (Sd). 